\title{
Metric Volumes for Plantation White Spruce
}

\author{
A. B. Berry \\ Research Scientist \\ Petawawa National Forestry Institute \\ Canadian Forestry Service \\ Chalk River, Ontario
}

With Canada's adoption of the metric system (SI) many forestry tables, previously prepared in the foot/pound units, will be converted to the new values. This paper presents the metric version of the white spruce (Picea glauca (Moench) Voss) volume table prepared by Berry (1969), and describes its derivation.

The data from 455 plantation grown white spruce at the Petawawa National Forestry Institute were available for analysis and conversion. The trees had been taken from unthinned plantations. For each tree the diameter at breast height, total height, and total wood volume (stump and top included) were listed. The total wood volume (in cubic feet) had been computed for each tree from a series of inside bark measurements from the stump to the top of the tree.

These data were converted to SI units using the following conversion factors:

$$
\begin{aligned}
& 1 \text { inch }=2.54 \mathrm{~cm} \\
& 1 \mathrm{ft}=0.3048 \mathrm{~m} \\
& 1 \mathrm{ft}^{3}=0.028316846 \mathrm{~m}^{3} .
\end{aligned}
$$

Since metric breast height is at $1.3 \mathrm{~m}$ instead of $4.5 \mathrm{ft}$ an adjustment in the tree diameters was made to take this into account by the formula from Berry (1978):

$$
\begin{gathered}
Y=-0.049+1.01 X \\
\text { where } Y=d_{1.3} \text { in centimetres } \\
X=d_{4.5} \text { in centimetres. }
\end{gathered}
$$

The data for all trees were combined and the following regression equation was derived:

$$
Y=0.0083+0.0327 X
$$

where $Y=$ volume in cubic metres

(stump and top included)

$$
\begin{aligned}
& X=\frac{D^{2} H}{1000} \\
& D=\text { diameter in centimetres at } 1.3 \mathrm{~m} \\
& H=\text { total height in metres. }
\end{aligned}
$$

The volumes by $2-\mathrm{cm}$ dbh classes and 2-m height classes are shown in Table 1.

\section{References}

Berry, A. B. 1969. Revised volume tables and taper curves for plantation white spruce. Canada, Dept. Fish. Forest., Inform. Rep. PS-X-9.

Berry, A. B. 1978. Metric yield tables based on site class and spacing for white spruce plantations at the Petawawa Forest Experiment Station. Canada, Dept. Fish. Environ., Inform. Rep. PS. $\mathrm{X}-70$.

Table 1. Metric volumes ${ }^{1}$ for plantation white spruce.

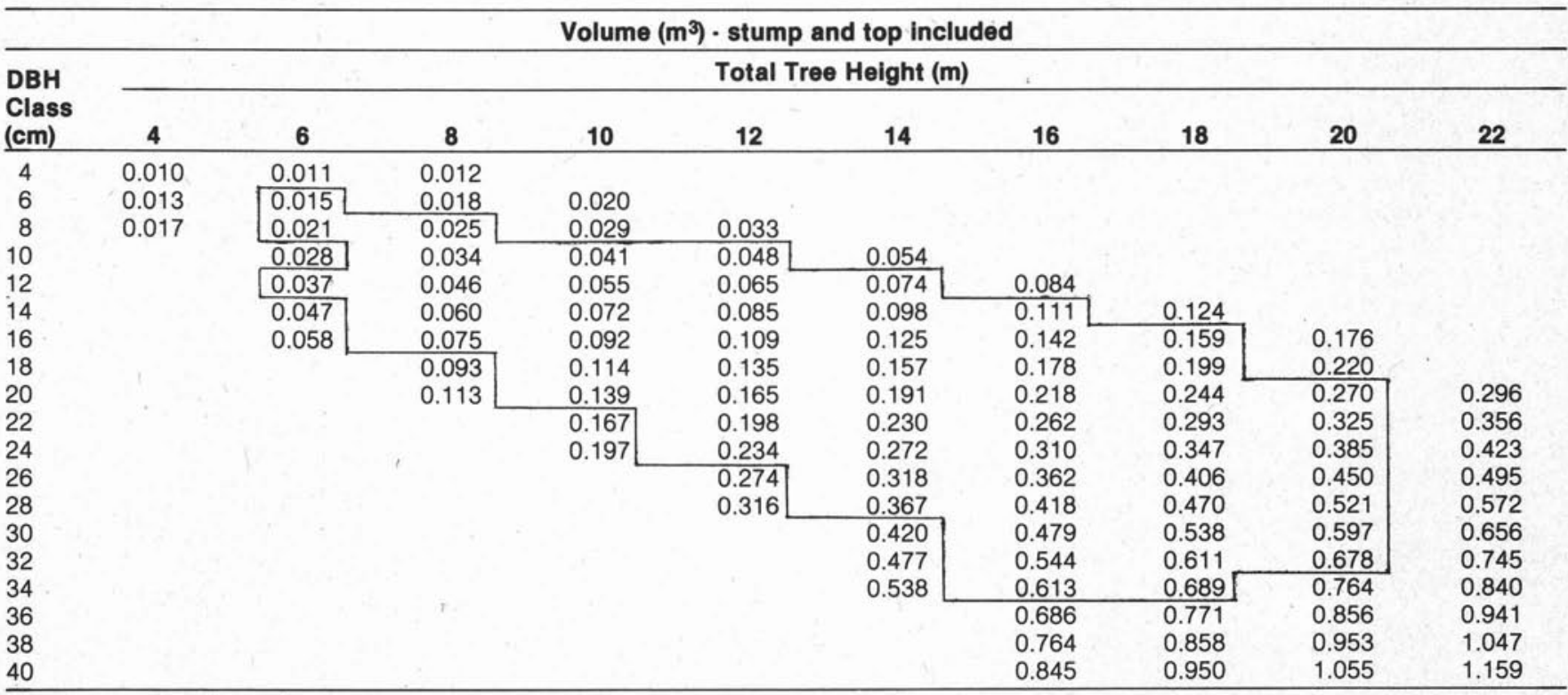

\footnotetext{
1Based on equation $Y=0.0083+0.0327 X \quad\left(R^{2}=.992\right)$

$$
\begin{array}{ll}
X= & \frac{D^{2} \mathrm{H}}{1000} \\
Y=\quad \text { total volume }\left(\mathrm{m}^{3}\right)
\end{array}
$$
}

Block indicates range of basic data from 455 trees measured at the Petawawa National Forestry Institute. 